\title{
Obesity and Its Risk Factors in Urban and Rural Females of Pune
}

\author{
Manisha A. Rathi*1, Dr. Ali Irani ${ }^{2}$, Dr. V. A. Kakrani ${ }^{3}$ \\ ${ }^{I}$ Dr. D. Y. Patil College of Physiotherapy, Dr. D. Y. Patil Vidyapeeth, Pimpri, Pune \\ ${ }^{2}$ Department of Sports and Physiotherapy, Balabhai Nanawati Hospital, Ville Parle(W), Mumbai \\ ${ }^{3}$ Dr. D. Y. Patil Medical College, Hospital and Research Center, Dr. D. Y. Patil Vidyapeeth, Pimpri, Pune
}

\begin{abstract}
:
Background of the study: Obesity is becoming a alarming metabolic disorders in global scenario. Its prevalence is increasing day by day even in developing countries. Urban population is more vulnerable to this epidemic specially females. Objectives of this study was to compare obesity and its risk factors in urban and rural females.

Methodology: In this cross sectional study, total 1063 females (545 rural and 518 urban) were analyzed. Height, weight, waist Circumference, Hip circumference, W:H ratio, Educational status, Socioeconomic status, Skinfold were measured. Body mass Index (BMI), Percentage of body fat were calculated using the formula. BMI classification, Cut off for Waist Circumference were considered as per guidelines given for Asian Indian Adults. Statistical significance was considered at $95 \%$ Confidence Interval.

Result: Out Of 1063 women randomly selected, $16.41 \%$ of urban and $10.83 \%$ of rural females were classified as overweight and $40.54 \%$ of urban and $22.75 \%$ of rural females were obese. Weight, BMI, Percentage of Body fat, Waist Circumference and Waist:Hip Ratio (WHR) was significantly higher $(p, 0.001)$ in Urban females as compare to Rural females.
\end{abstract}

Conclusions: The higher prevalence of overweight and obesity was found in Urban women as compared to Rural women. Urban females were more central obese than Rural females.

Key Words: Obesity, BMI, Body fat percentage, Urban and Rural Females.

\section{Introduction:}

Obesity is a chronic, multifactorial disease with complex psychological, environmental (social and cultural), genetic, physiologic, metabolic and behavioral causes and consequence (American Obesity Association). Obesity has reached at an alarming rate (Flegal et al. 2002, Hedley et al. 2004) ${ }^{1,2}$ and prevalent among all the groups of adults especially in women in both developed and developing countries (Wang and Hoy, 2004; Flegal, 2005). ${ }^{3,4}$ Environmental and behavioral changes brought about by economic development, modernization and urbanization have been linked to the rise in global obesity ${ }^{5}$. Obesity epidemic has important public health consequences because obesity is associated with numerous disease and disability (Visscher and Seidell, 2001) ${ }^{6}$ and shorter life expectancy (Olshansky et al 2005) ${ }^{7}$.

Females experience one or several life changing experiences that makes them vulnerable to weight gain. Pregnancy and post delivery period leads to significant amount of fat mass retention (Rathi M. and Palekar $\mathrm{T} 2012)^{8}$, Changes in social roles such as entering or leaving marriage influence physical characteristics such as body weight. Females who were unmarried at the baseline and married at follow-up showed greater weight change than those who were married at both times. ${ }^{9}$

Zargar AH at el (2004) stated that Obesity is a growing problem even in developing regions like India and is more common in females and in urban population. ${ }^{10}$ Shah Ebrahim, et al ( 2010) studied that Migration into urban areas is associated with increases in obesity, which drive other risk factor changes. ${ }^{11}$ Whereas Christie A et at (2012) observed in a study done in united states that prevalence of obesity in rural adults was $39.6 \%$ and urban adults was $33.4 \% .{ }^{12}$ This is in contrast to the findings observed in India. A study done by Kaur et al (2013) found that Prevalence of Overweight is $75.33 \%$ in Urban and $67.99 \%$ in Rural women. ${ }^{13}$ Long-term weight loss strategies are of limited success ${ }^{14}$, and the costs associated with obesity treatment are high ${ }^{15}$. Obesity prevention is therefore an important public health priority and for this it is necessary to know the weight status of urban and rural females

Hence this study aimed to describe and compare the body compositions of the females of childbearing age from urban and rural areas.

\section{Methodology}

In this Cross sectional study, a Total 1063 females were included out of which 545 were from rural area and 518 from urban area of Pune. Ethical approval was taken from Institutional Ethical Committee. Data was collected from January 2013- March 2014. Females from the age group of $20-45$ were included in the 
study. Pregnant, Post partum, menopausal females and Physically disabled females were excluded from the study. Written consent was taken from all the participant. Demographic data like no. of children, Education level, Monthly Income, Working Status was assessed for all participants. Socioeconomic status was assessed using the Kuppuswami's Socioeconomic Status Scale as revised in $2012 .{ }^{16}$ The anthropometric measurements were taken by using standard technique recommended by Lohman et al $1988 .{ }^{17}$ Body weight and height measurements were made two times and Average was considered the final reading. Body weight was measures to the nearest $0.1 \mathrm{Kg}$ using digital electronic scale with the subject wearing minimum clothes and height was measured to the nearest $0.1 \mathrm{~cm}$ using stadiometer. Skinfold Measurements were taken at Chest, Subscapular, Thigh, Abdomen, Triceps, Midaxillary and Suprapubic area as per ACSM Guidelines. ${ }^{18}$ All the skinfold measurements were taken to the nearest $1.0 \mathrm{~mm}$ using Skinfold caliper. Readings were measured at three times and average was considered as the final reading. Body Mass Index (BMI) and Waist Hip Ratio (WHR) was calculated through following equations, BMI = Weight $(\mathrm{Kg}.) /(\text { Height in } \mathrm{cm})^{2}$, WHR $=$ Waist Circumference in $\mathrm{cm} /$ Hip Circumference in $\mathrm{cm}$. Body Density was calculated using 7 site formula for females and Body Density was converted into Percentage of Body Fat By using Siri's Equation where percent body fat $=100$ [ ( 4.94/Body Density) $-4.50{ }^{19}$. BMI was categorized as Normal, Underweight, Overweight \& obese using Indian classification and Cut off values for waist Circumference was considered $80 \mathrm{~cm} \cdot{ }^{20}$ Data was analyzed and statistical significance was considered at $95 \%$ Confidence Interval.

\section{Results}

The present study has included 1063 females of the reproductive age group from Urban $(\mathrm{n}=518)$ and rural $(n=545)$ area. The mean and standard deviation of age, anthropometric variables and adiposity indices of the two groups are described in the Table 1.

The overall prevalence of overweight was $13.55 \%$ ( $95 \% \mathrm{CI}-0.11$ to 0.15 ) and that of obesity was $31.42 \%$ ( $95 \% \mathrm{CI}-0.28$ to 0.34 ). Table 1 shows the prevalence of Overweight and obesity in urban and Rural females and it reveals that Urban female have higher prevalence in overweight and obesity than rural females. In the table 2, When compared, BMI and percentage of Body Fat of Urban females was found statistically higher than that of the Rural females as $p<0.000$. The Central obesity was significantly higher in urban females than rural females as observed by waist circumference and W:H Ratio. As per the cut off values given for the waist circumference for predicting the risk of developing cardiovascular diseases, $62 \%$ urban females showed waist circumference more than $80 \mathrm{~cm}$. whereas only $33 \%$ rural females had more circumference.

Interestingly it has been found and seen in the graph 1, the educational status increases from $1-7$ as described in Kuppuswami Scale, the Mean BMI increases. Illiterate and primary educated females showed lesser BMI than Professionals and highly educated. Percentage of females who has obesity increases with the education level. We also found in the graph 2 that females with lower Socioeconomic status were lean than females with higher socioeconomic status.

Table 1. Percentage of Prevalence of Overweight and Obesity among Urban and Rural Women of Pune according to the South East Classification of BMI.

\begin{tabular}{|l|l|l|l|}
\hline Prevalence of & Overall & Urban $(95 \% \mathrm{CI})$ & Rural $(95 \% \mathrm{CI})$ \\
\hline Underweight & $13.92 \%$ & $8.49 \%(6.30-11.32)$ & $19.08 \%(15.92-22.69)$ \\
\hline Normal weight & $41.11 \%$ & $34.56 \%(30.49-38.85)$ & $47.34 \%(43.09-51.63)$ \\
\hline Overweight & $13.55 \%$ & $16.41 \%(13.38-19.95)$ & $10.83 \%(8.40-13.81)$ \\
\hline Obesity & $31.42 \%$ & $40.54 \%(36.30-44.92)$ & $22.75 \%(19.34-26.55)$ \\
\hline
\end{tabular}

Table 2

\begin{tabular}{|c|c|c|c|c|}
\hline Particulars & Overall & Urban & Rural & $\mathrm{P}$ value \\
\hline Mean Age in Yrs. & $32.36(\mathrm{SD}=7.07)$ & 33. $11(\mathrm{SD}=7.02)$ & $31.65(\mathrm{SD}=7.06)$ & $\mathrm{P}<0.001$ \\
\hline Mean Height in $\mathrm{cm}$. & $1.54(\mathrm{SD}=0.04)$ & $1.56(\mathrm{SD}=0.05)$ & $1.53(\mathrm{SD}=0.04)$ & \\
\hline Mean Weight in Kg. & $55.04(\mathrm{SD}=6.43)$ & $59.08(\mathrm{SD}=11.03)$ & $51.20(\mathrm{SD}=8.89)$ & $\mathrm{P}<0.001$ \\
\hline Mean BMI $\left(\mathrm{Kg} / \mathrm{M}^{2}\right)$ & $23.01(\mathrm{SD}=1.14)$ & $24.24(\mathrm{SD}=4.33)$ & $21.84(\mathrm{SD}=3.60)$ & $\mathrm{P}<0.0001$ \\
\hline $\begin{array}{l}\text { Mean Waist Circumference } \\
\text { in } \mathrm{cm} \text {. }\end{array}$ & $81.30(\mathrm{SD}=4.24)$ & $85.04(\mathrm{SD}=10.29)$ & $77.75(\mathrm{SD}=10.00)$ & $\mathrm{P}<0.001$ \\
\hline Mean Waist Hip Ratio & $0.83(\mathrm{SD}=0.06)$ & $0.84(\mathrm{SD}=0.053)$ & $0.83(\mathrm{SD}=0.049)$ & $\mathrm{P}=0.009$ \\
\hline $\begin{array}{l}\text { Mean Percentage of Body } \\
\text { fat }\end{array}$ & $26.34(\mathrm{SD}=11.98)$ & $30.20(\mathrm{SD}=7.39)$ & $22.66(\mathrm{SD}=7.32)$ & $P<0.001$ \\
\hline
\end{tabular}


Graph 1: As education level increases from 1 to 7 , the mean BMI increases significantly $(\mathrm{p}<0.001)$

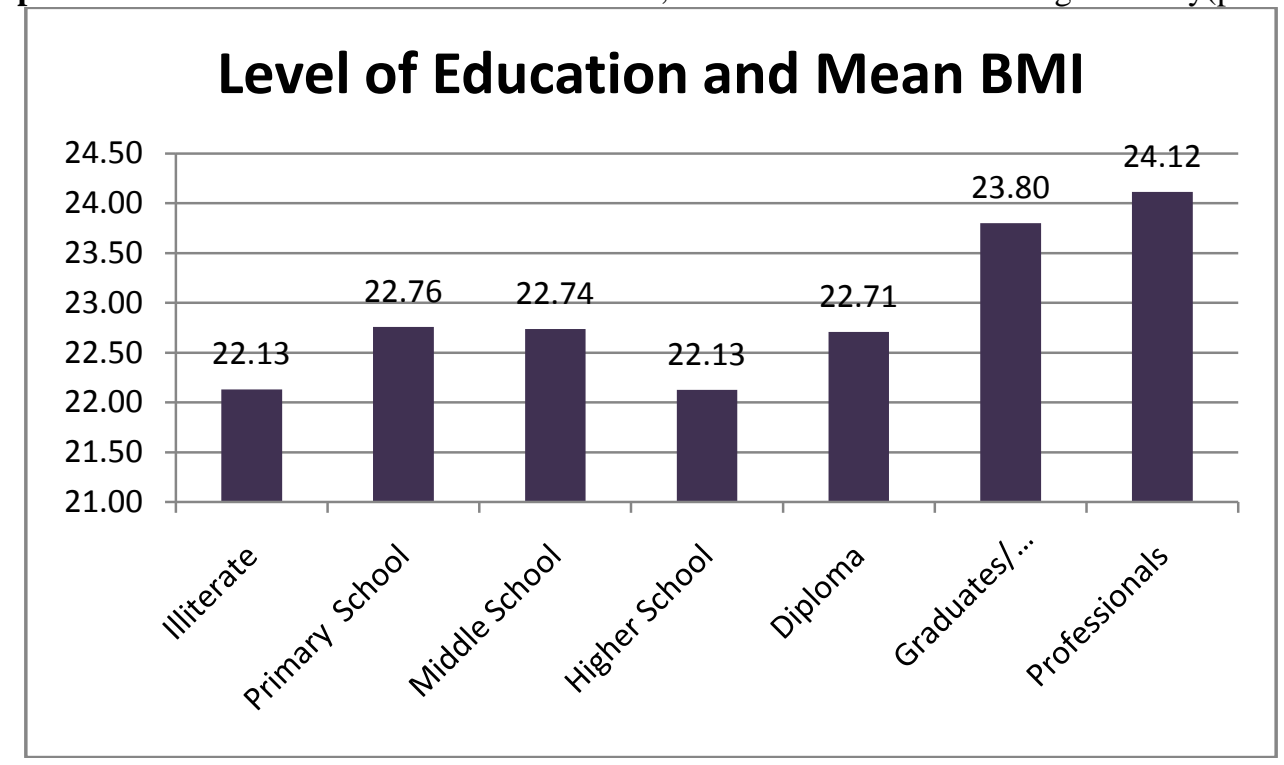

Graph 2: As Socioeconomic status lowers, the percentage of females who has BMI decreases significantly $(\mathrm{p}<0.001)$.

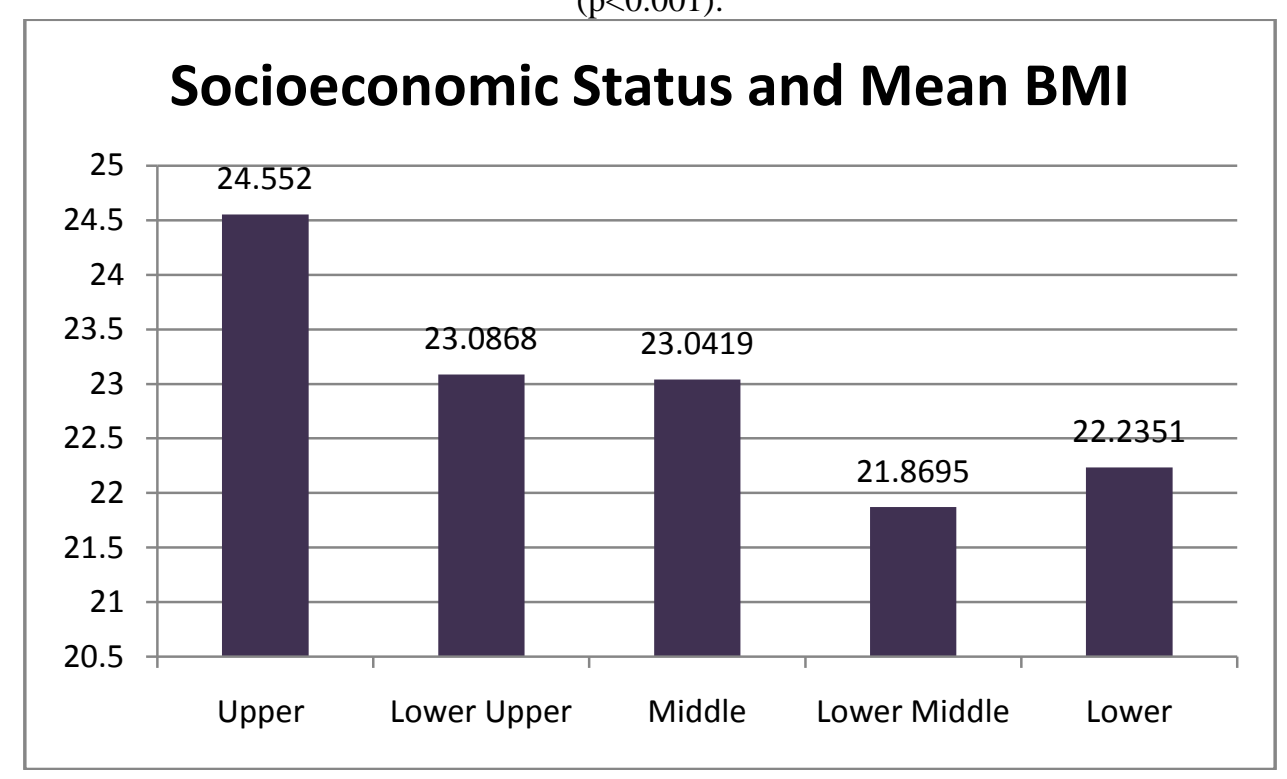

\section{Discussion}

The present study found the higher rate of prevalence of overweight and obesity in the females of reproductive age from Urban area than the Rural area. The result of this study showed the similar results by the study done in the India by Gurjeet Kaur et al (2013). ${ }^{13}$ They found prevalence of obesity was $29.33 \%$ in urban women and that in the rural women was $17 \%$. A study done by Mendez et al (2005) also reported that prevalence of overweight and obesity was higher in urban women than rural women ${ }^{21}$.

Urbanization mainly leads to the changes in the occupation patterns, lifestyle, family structures and to some extents also value system. These changes are reflected changes in the diatary pattern and the level of the physical activity. As the people are showing increase in the socioeconomic status, cereals intake declines and intake of fast food, sugar and fat is increasing. In urban population, consuming easily available food, more of sedentary lifestyle is occurring in the context of globalization. While the rural population is mainly involves in farming work whivh involves more of manual labour, and a high level of physical activity, urban population is involved in skilled or semiskilled work which mainly leads to sedentary lifestyle except for some of the urban slum dwellers. These changes in the dietary practices, physical activity and lifestyle are associated with rising affluence induced by developmental transition which ultimately contribute to the increasing prevalence of overweight and obesity in urban areas. 
The result of this study was contradictory to the findings of the study done by Patterson et al 2004 where they reported that obesity was more common in rural adults $(20.4 \%)$ than urban adults $(17.8)^{22}$. Similar results was also reported by Verity Cleland et al (2010) as they found $24 \%$ of urban and $26 \%$ of rural women were classified as overweight and $19 \%$ of urban and $23 \%$ of rural women were classified as obese ${ }^{23}$. Here they showed Prevalence of obesity and overweight was higher in rural females as compare to urban females.

We found that the females having higher Socioeconomic status were more overweight and obese than the lower socioeconomic status. In developing countries like India, Higher socioeconomic status relates with less physical activity and more sedentary lifestyle. On the contrary, it has been observed in US that females with lower income had higher BMI and Body weight that the females with Higher BMI. (Couzelis, 2005) ${ }^{24}$.

Percentage of Body Fat was found more in Urban females that rural females. Rural females involve in activities like washing clothes by hands, doing all household work, Farming work, and also the mode of transport is walking. Physical activities lead to development of lean body mass and reduction of fat mass. Brownson et al (2000) found that rural females spent more time doing household physical activity than the females who resided in more densely populated metropolitan communities ${ }^{25}$. This higher level of household activity in the rural females can be due to the limited access to and the higher cost of services that support household functions. This leads to the more energy expenditure and ultimately leads to less percentage of body fat and weight.

Further research can be done on prevalence of overweight and obesity with working status, parity status and diet pattern of the females from urban and rural females.

This study concludes that the urban females have more prevalence of Overweight and obesity than the rural females and more central obesity than Rural females. It is also concluded that education and socioeconomic status inversely affects BMI.

\section{Acknowledgement:}

Authors are thankful to all the people who helped directly and indirectly in completing this research. Authors are extremely thankful to Dr. S. Jadhav, Professor, Dr. D. Y. Patil medical College, Hospital and Research Centre, Pimpri, Pune for doing the statistical analysis of the dlstudy.

\section{Conflict of Interest :-}

Conflict of Interest declared none.

\section{References}

[1]. Flegal KM, Carroll MD, Ogden CL, Johnson CL (2002) Prevalence and trends in obesity in obesity among US adults 1999-2000. JAMA. 288, 1723-27

[2]. Hedley A A, Ogden CL, Johnson CL, Carroll M D, Curtin LR, Flegal KM, 2004. Prevalence of overweight and Obesity among US children, adolescents and Adults, 1999-2002. JAMA.291:2847-50

[3]. Wang Z, Hoy W E. (2004) Waist Circumference, Body Mass Index, Hip Circumference and Waist-to-Hip ratio as predictor of Cardiovascular Disease in Aboriginal People. Eur. J. Clin. Nutr. 58: 888 - 893.

[4]. Flegal K M, (2005) Epidemiological Aspects of Overweight and Obesity in United Status. Physiol. Behav. $86: 599$ - 602.

[5]. Iram SK, Faryal M, Arshad I S. Prevalence of Impaired Glucose Tolerance among Obese Ann. Pak. Inst. Med. Sci. 2008;4(3): 168170

[6]. Visscher TL, Seidell JC. 2001. The public health impact of obesity. Annu. Rev. Public Health. 22: 355-75

[7]. Olshansky SJ, Passaro DJ, Hershow RC et al 2005, “A Potential Decline in life Expectancy in the United States in the 21 Century, N. Engl. J. Med: 352: $1138-45$

[8]. Manisha Rathi, Tushar Palekar, "A Study of weight and girth variations during pregnancy and post partum in Underweight, normal and Overweight women” Indian Journal Of Physiotherapy and Occupational Therapy, 2012;6(4): 178-81

[9]. Sobal J, Rauschenbach B, and Frongillo EA. Marital Status changes and body weight changes: A US Longitudinal Analysis. Social Science and Medicine. 2003;56(7):1543-1555.

[10]. Zargar A H, Masoodi SR, Laway BA, Wani AI, Bashir MI, Akhtar S. Prevalence of Obesity in adults - an epidemiological study from Kashmir Valley of Indian Subcontinent.

[11]. Ebrahim S, Kinra S, Bowen L, Andersen E, Ben-Shlomo Y, et al (2010) The Effect of Rural-to-Urban Migration on Obesity and Diabetes in India: A Cross-Sectional Study. PLoS Med 7 (4):e 1000268. Doi:10.1371/journal.pmed.1000268.

[12]. 12.Christie A. Befort, Niaman Nazir, \& Michael G. Perri, Prevalence of Obesity Among Adults From Rural and Urban Areas of the United States: Findings From NHANES (2005-2008), The Journal of Rural Health 28 (2012) 392-397

[13]. Gurjeet Kaur, S.P. Singh and Ajipal Singh,(2013) Prevalence of Overweight and Obesity in Urban and Rural Women of Punjab.Human Biology Review ; 2(4):306 -313.

[14]. World Health Organization. Obesity: preventing and managing the global epidemic. Geneva: WHO, 2000.

[15]. Access Economics. The economic costs of obesity. Report by Access Economics Pty Ltd to Diabetes Australia. Canberra: Diabetes Australia, 2006)

[16]. BP Ravi Kumar*, Shankar Reddy Dudala, AR Rao, "Kuppuswamy’s socio-economic status scale - A revision of economic parameter for 2012" International Journal of Research \& Development of Health. Jan 2013; Vol 1(1): 2-4.

[17]. Lehman TG, Roche AF, Marforell ER 1988. Anthropometric Standardization Referecnse Manual . Campaign IL : Human Kinetics . Champaign, IL.

[18]. ACSM. ACSM's Guidelines for Exercise Testing and Prescription . Sixth Edition . Philadelphia. Li ppincott Williams and Wilkins 2000 .

[19]. Siri WE. Techniques for measuring body composition. Washinton, DC: National Academy of Sciences, 1961. 
[20]. Chamukuttan Snehalatha, Vijay Viswanathan and Ambady Ramachandran, Cutoff values for Normal Anthropometric Variables in Asian Indian Adults, Diabetes Care, volume 26, number 5, may 2003; 1380-1384,

[21]. Mendez MA, Monteiro CA, Popkin BM.2005. Overweight exceeds underweight among women in most developing countries. Am. J. Clin. Nutr.81:714 -21.

[22]. Patterson PD, Moore CG, Probst JC, Shinogle JA( 2004): Obesity and Physical Inactivity in Rural America : The Journal of Rural health; Vol. 20, Issue 2; 151-159

[23]. Verity Cleland, Clare Hume, David Crawford, Anna Timperio, Kylie Hesketh, Louise Baur, Nicky Welch, Jo Salmon and Kylie Ball ( 2010) Urban-rural comparison of weight status among women and children living in socioeconomically disadvantaged neighbourhoods. MJA 2010; 192: 137-140

[24]. Couzelis, P. (2005). The business side: the often overlooked personal cost of obesity. American College of Sports Medicine. 9(1): 32-33.

[25]. Brownson RC, Eyler AA, King AC, Brown DR, Shyu YL, Sallis JF. Patterns and correlates of physical activity among U.S. women 40 years and older. American Journal of Public Health. 2000; 90:264-270. 